\title{
Brachytherapy for Recurrent Single Brain Metastasis
}

\author{
Mark Bernstein, Alberto Cabantog, Normand Laperriere, Phil Leung and \\ Cindy Thomason
}

\begin{abstract}
Of 112 stereotactic high-activity iodine- 125 implants for malignant brain tumors done as of July 1, 1994, ten have been done for recurrent single brain metastasis and constitute the study group described herein. All patients had initially undergone craniotomy for tumor resection followed by fractionated external beam whole brain radiation and recurred at the same site in the brain. The interval between initial cancer therapy and occurrence of the brain metastasis was $13-156$ weeks (median: 63 weeks). The interval between initial treatment of the brain metastasis and its recurrence treated with brachytherapy was 13 - 69 weeks (median: 35 weeks). Minimum brachytherapy dose administered was $70 \mathrm{~Gy}$ at a median dose rate of $67 \mathrm{cGy} / \mathrm{hour}$. Eight patients have died. Two died suddenly at 2 and 13 weeks post-implant of presumed pulmonary embolus. Five died of recurrence of the brain metastasis at 20,39,52,103, and 143 weeks post-implant, and one died of systemic metastases at 40 weeks post-implant. Two patients remain alive 183 and 324 weeks post-implant. High-activity iodine-125 brachytherapy appears to be of benefit for selected patients with recurrent single brain metastasis but larger, and preferably randomized studies are needed.
\end{abstract}

RÉSUMÉ: Curiethérapie pour une métastase cérébrale unique récidivante. Parmi les 112 implants d'iode125 fortement radioactif faits par stéréotaxie pour traiter des tumeurs cérébrales malignes en date du premier juillet 1994, nous présentons les dix cas d'implants faits pour une métastase cérébrale unique récidivante. Tous les patients avaient subi initialement une crâniotomie pour résection d'une tumeur, suivie de radiothérapie fractionnée par faisceau externe à tout le cerveau. La récidive était localisée au même site que la tumeur initiale dans le cerveau. L'intervalle entre le traitement anticancéreux initial et le développement de la métastase cérébrale était de 13 - 156 semaines (médiane: 63 semaines). L'intervalle entre le traitement initial de la métastase cérébrale et sa récidive traitée par curiethérapie était de 13 - 69 semaines (médiane: 35 semaines). La dose minimum administrée était de $70 \mathrm{~Gy}$ à un taux médian de $67 \mathrm{cGy}$ à l'heure. Huit patients sont décédés. Deux sont morts subitement 2 et 13 semaines post-implant, présumément d'embolie pulmonaire. Cinq sont morts d'une récidive de la métastase cérébrale 20,39,52, 103, et 143 semaines post-implant, et un est mort de métastases généralisées 40 semaines post-implant. Deux patients sont toujours vivants 183 et 324 semaines post-implant. La curiethérapie par l'iode- 125 fortement radioactive semble être bénéfique chez certains patients qui ont une métastase unique récidivante. Cependant des études plus considérables, préférablement randomisées, sont nécessaires.

Can. J. Neurol. Sci. 1995; 22: 13-16

For good surgical risk patients with single brain metastasis and stable primary disease, surgery followed by whole brain irradiation produces better palliation and longer median survival than either modality alone. ${ }^{1-3}$ However, once these measures fail, there are few effective treatment options available and survival is short despite good control of the primary disease in many cases. Reoperation with its attendant risk, benefits only a very few patients for a short time while chemotherapy is generally ineffective. Re-irradiation with fractionated external beam therapy has modest success in highly selected patients and exposes the brain to a significant risk of symptomatic radiation necrosis. ${ }^{4.5}$ There has recently been interest in focal radiation for recurrent brain metastases, either by external beam (i.e., radio- surgery) or interstitial (i.e., brachytherapy). ${ }^{6-9}$ These modalities can deliver a high total dose of radiation to the tumor volume with acceptable risk of radiation damage to the surrounding normal brain. ${ }^{10}$ Prados et al. have reported that brachytherapy as

From the Division of Neurosurgery (M.B., A.C.), The Toronto Hospital, Departments of Radiation Oncology (N.L.) and Physics (P.L., C.T.), Princess Margaret Hospital, University of Toronto, Toronto.

RECEIVED JULY 12, 1994. ACCEPTED IN FINAL FORM AUGUST 30, 1994

Reprint requests to: Mark Bernstein, MD. FRCSC, Division of Neurosurgery, The Toronto Hospital, Suite 2-405, McLaughlin Pavilion, 399 Bathurst Street. Toronto, Ontario, Canada M5T 2S8 
part of the initial therapeutic plan or at time of recurrence can offer palliation and prolong survival in selected patients. ${ }^{9}$ Kreth et al. have also demonstrated efficacy of brachytherapy both for de novo single metastases and for recurrent disease. ${ }^{8}$ We report herein our small experience with high-activity iodine-125 brachytherapy for highly selected patients with local recurrence of a single cerebral metastasis after conventional treatment with surgery plus external beam irradiation.

\section{Patients And Methods}

Among the 112 adult patients with malignant brain tumors who have been treated with stereotactic high-activity iodine- 125 implants at The Toronto Hospital as of July 1, 1994, ten were treated for recurrent single metastatic brain tumor. All ten patients had initially undergone craniotomy for tumor resection followed by fractionated external beam whole brain radiation ( $20 \mathrm{~Gy}$ in 5 fractions or $30 \mathrm{~Gy}$ in 10 fractions). Patients were selected for brachytherapy if the tumor recurred at the same site in the brain and if they were in good neurological condition with Karnofsky performance status 70 or better, with stable systemic disease (i.e., no evidence of disease activity outside the brain).

There were 7 women and 3 men, with a mean age of 54.2 years and a median age of 57.5 years (range: $35-66$ years). The primary tumor was adenocarcinoma in all 10 patients with nine originating in the lung and one originating in the breast. Nine tumors were located in the cerebral hemisphere and one in the cerebellum. The brain metastasis appeared 13-156 weeks (median: 63 weeks) after initial diagnosis and treatment of the primary cancer (i.e., lung or breast tumor). Brachytherapy was instituted when the patient developed definite imaging evidence of recurrence of the brain tumor. Four of the ten patients underwent surgical debulking of recurrent brain tumor weeks to months prior to brachytherapy. The interval between initial treatment of the brain metastasis and treatment of the recurrence with brachytherapy was 13-69 weeks (median: 35 weeks).

The implantation technique and dosimetry have been described in a previous report." High-activity iodine- 125 seeds (20 to $40 \mathrm{mCi}$ ) were implanted under local anesthesia using the Brown-Roberts-Wells CT-guided stereotactic system. Minimum dose prescribed to the periphery of the tumor was $70 \mathrm{~Gy}$ in all ten cases; the median dose rate of delivery was $67 \mathrm{cGy} / \mathrm{hour}$ (mean: $67.3 \mathrm{cGy} / \mathrm{hr}$ ). Seven implants were done utilizing a single catheter; two implants used two catheters and one used three. Total iodine-125 activity ranged from 116.5 to $552.6 \mathrm{mCi}$ (mean: $275.3 \mathrm{mCi}$; median: $236.0 \mathrm{mCi}$ ). Implant volume ranged from $12.1 \mathrm{cc}$ to $99.0 \mathrm{cc}$ (mean: $44.5 \mathrm{cc}$; median: $36.4 \mathrm{cc}$ ). Patients were followed in a multi-disciplinary neuro-oncology clinic with neurological examination and CT or MRI every three months, and whenever clinically indicated.

\section{Results}

As of July 1, 1994, eight patients have died. Two died suddenly at two and 13 weeks post-implant of presumed pulmonary embolus. Five died of recurrence in the brain at 20, 39, 52, 103, and 143 weeks post-implant; one of these recurrences was at a site distant from the brachytherapy site. These five patients were not offered further therapy because of the diffuse nature of the recurrence and/or their poor functional status. One patient died of systemic metastases at 40 weeks post-implant; at the time of her death there was no evidence of disease activity in the brain. Two patients remain alive and disease-free at 183 , and 324 weeks post-implant; both patients have significant hemiparesis which has been slowly progressive since the implant. The median survival post-implant with two still alive is 46 weeks (product limit estimate method), although this calculation may have limited meaning because of the small size of the study group. From the time of first diagnosis of the brain metastasis to death or most recent follow-up, survival ranges from 8-87 months; nine of ten patients have survived at least one year and five patients have lived at least two years. From the time of first diagnosis of cancer in the lung or breast to death or most recent follow-up, survival ranges from 11-101 months; nine of ten patients have lived longer than one year, seven of ten have lived at least two years, and five patients have lived at least three years following the diagnosis of cancer.

Three patients underwent re-operation at the initially treated site for symptomatic mass lesion 60,69 and 138 weeks postimplant. In two patients there was pathological evidence of radiation necrosis only; in the other, the histology was that of mixed tumor and radiation necrosis. All three re-operated patients are among the four long-survivors post-implant (i.e., two died at 103 and 143 weeks post-implant and the other is alive 183 weeks post-implant). The fourth long-survivor who is alive 324 weeks post-implant did not undergo re-operation. There were two patients who developed complications attributable to the implant. Both incurred permanent worsening of pre-existing motor weakness following implants for tumors in the motor cortex. One of these patients also had a flurry of focal motor seizures within weeks of the implant; the seizure pattern in this patient eventually settled back to the pre-implant base-line.

\section{DiscuSSION}

Improvements in the treatment of systemic cancer have resulted in prolonged survival and, concomitantly, increased incidence of metastases to the CNS. ${ }^{1}$ Approximately 25 to 30 percent of cancer patients develop intracranial metastases in the course of their disease. ${ }^{12}$ Advances in neuroimaging have led to the early detection of brain metastases leading to prompt and early treatment. Brain metastases become symptomatic early in their course and usually are more overt and disabling than metastases in other organs. If untreated, they cause death within months.

Initial therapeutic options for a brain metastasis depend on the patient's clinical status (e.g., age, functional status, medical problems, control of systemic cancer) and tumor characteristics (e.g., histology, location, size, number). Survival is likely longer for patients with no disseminated cancer, good performance status and a single supratentorial lesion in the brain. ${ }^{13-15}$ The median survival of this group of patients undergoing surgical resection followed by whole brain radiation ranges from $6-24$ months. 2,3,13 The rationale for postoperative whole brain radiation is the assumption that no matter how thoroughly the mass lesion was removed, there are still tumor cells left behind in the tumor bed. An additional compelling argument for whole brain radiation is the belief that there are already microscopic hematogenolis metastases at distant sites in the brain at the onset of symptoms from the obvious metastasis seen on imaging. 
However, in a small series of 33 surgically treated patients, Dosoretz et al. reported no difference in survival between patients treated with surgery alone and those treated with surgery plus teletherapy. ${ }^{16}$ However, the higher local recurrence rate generally observed for patients treated with surgery alone has lead most clinicians to recommend postoperative wholebrain radiation to all their patients following resection of a solitary brain metastasis.

Therapeutic options for recurrent brain metastasis are limited after surgery and radiation therapy have been previously used. The blood-brain barrier (in part) has rendered chemotherapy for brain tumors less effective than for the primary disease. ${ }^{17.18}$ However, several authors have challenged this concept and they in fact have reported encouraging results with various combinations of chemotherapeutic agents including the utilization of intracarotid infusion. ${ }^{19,20}$

Re-irradiation by fractionated external beam therapy is limited because of the cumulative risk of radiation necrosis in the surrounding normal brain, but in highly selected patients, this treatment may provide modest neurological improvement and prolongation of life.,5 Simple repeat surgical excision is limited by the lack of discreteness of the recurrent tumor borders (compared to the initial metastasis) and the attendant risk of surgery of an intra-axial lesion. ${ }^{21}$

The use of interstitial brachytherapy as part of the initial therapeutic regimen has been reported both for primary and secondary brain tumors. Highly selected patients with glioblastoma multiforme initially treated with external beam radiation survived longer when treated with adjuvant brachytherapy than those treated without. ${ }^{22}$ Randomized studies are ongoing to determine if brachytherapy indeed prolongs the survival of patients with glioblastoma treated "up-front"." There is limited experience in the use of brachytherapy "up-front" in the treatment of brain metastases. Kreth et al. treated 38 patients with iodine-125 brachytherapy (minimum dose: $60 \mathrm{~Gy}$ ) and whole brain fractionated radiation (dose: $40 \mathrm{~Gy}$ ); median survival in this group was 17 months. ${ }^{8}$ These authors also treated 22 patients with brachytherapy alone (i.e., without external beam irradiation) and observed a median survival of 12 months in the latter group. These figures compare favourably with a median survival of 7.7 months for 49 patients treated with external beam radiation alone. ${ }^{8}$ Prados et al. treated a small number of patients with iodine- 125 brachytherapy used as a "boost" given immediately after external radiation for a newly diagnosed brain metastasis; three of four patients so treated lived more than one year following brachytherapy. ${ }^{9}$

There have been several reports regarding the efficacy of interstitial brachytherapy for selected patients with recurrent malignant glioma, meningiomas and skull base tumors. ${ }^{11,23,26}$ There is limited experience with this modality reported for recurrent solitary cerebral metastases. Heros et al., reported 3 cases of recurrent solitary brain metastasis treated with iridium192 brachytherapy. ${ }^{7}$ Two of the three patients were felt to have sustained a useful prolongation of survival. Kreth et al. reported a median survival of 6 months in a group of 21 patients with recurrent brain metastasis treated with brachytherapy. ${ }^{8}$ In the patients reported by Prados et al., of nine treated with brachytherapy for recurrent brain metastasis, seven lived longer than one year following the implant. ${ }^{9}$
In a discussion of brachytherapy for brain metastases, one must consider the other popular form of focal radiation - radiosurgery either by gamma knife or linear accelerator. ${ }^{6}$ This modality has a number of advantages over brachytherapy: 1) it is non-invasive and therefore spares the patient the potential catheter-related risks (e.g., infection, hemorrhage); 2) it takes less time in hospital which is a significant factor for these patients who have already undergone a number of surgical and other medical interventions. The major disadvantages of radiosurgery are: 1) one is more restricted in the size of the lesion that can be treated; 2) radiobiologically, the rationale for radiosurgery is inferior to that of brachytherapy because the drop-off of dose is more gradual for interstitial implants, which may improve the local tumor control as more microscopic disease in the periphery of the tumor volume is exposed to a higher dose of radiation in a well-planned implant than in a well-planned radiosurgical treatment. The latter point is more relevant to a discussion of gliomas, as gliomas are more infiltrative beyond margins appreciated on imaging than are metastases. Preliminary results of the radiosurgical treatment of metastatic brain tumors are encouraging, ${ }^{6}$ but dogmatic statements about the relative efficacy of this modality cannot be made because, as in our present study, highly selected patients are being treated in non-randomized trials.

Our ten patients represent a small, relatively homogeneous group and the treatment was consistent within the group. However there is a prominent selection bias and there is no adequate control group to compare our treatment group to. The patients were extremely highly selected in that they recurred only at the previously treated site in brain while their systemic disease remained quiescent. These patients clearly represent a subset of metastatic cancer patients with disease of relatively favourable biology, in spite of the fact that they had developed a metastasis in the brain. However, all the patients except the two who died early on of apparent pulmonary embolus derived a beneficial response, with survivals ranging from 20 to 324 weeks and two patients still alive. Five patients lived at least one year following brachytherapy. Even in this group of patients with tumors of favourable biology, death would likely have ensued in weeks to months following symptomatic recurrence, had experimental therapy not been given. Of course, one cannot state definitively whether or not any other experimental modality might have worked as well or better in this highly selected population.

Brachytherapy for brain metastasis is still very much in its infancy. There are numerous unresolved questions regarding both technical aspects and patient selection. Controlled randomized studies of the different therapeutic options, in combination or alone, for recurrent metastases are necessary to determine the best form of treatment for this group of patients. An ideal study would be a randomized multi-center trial of brachytherapy versus radiosurgery for patients with recurrent solitary brain metastasis. As potent an adjuvant therapy as brachytherapy may appear to be, the relative success of this and other experimental modalities may be largely a function of super-selection of patients with relatively favourable biology who would do relatively well whatever treatment was selected. 


\section{REFERENCES}

1. Black P. Brain metastasis: Current status and recommended guidelines for management. Neurosurgery 1979; 5: 617-631.

2. Patchell RA, Cirrincione C, Thaler HT, Galicich JH, Kim JH, et al. Single brain metastases: surgery plus radiation or radiation alone. Neurology 1987; 36: 447-453.

3. Patchell RA, Tibbs PA, Walsh JW, Dempsey RJ, Maruyama Y, et al. A randomized trial of surgery in the treatment of single metastases to the brain. N Engl J Med 1990; 322: 494-500.

4. Cooper JS, Steinfeld AD, Lerch IA. Cerebral metastases: value of reirradiation in selected patients. Radiology 1990; 174: 883-885.

5. Hazuka MB, Kinzie JJ. Brain metastases: results and effects of reirradiation. Int J Rad Onc Biol Phys 1988; 15: 433-437.

6. Engenhart R, Kimmig BN, Hover K, Wowra B, Romahn J, et al. Long-term follow-up for brain metastases treated by percutaneous stereotactic single high-dose irradiation. Cancer 1993; 71: 1353-1361.

7. Heros DO, Kasdon DL, Chun M. Brachytherapy in the treatment of recurrent solitary brain metastasis. Neurosurgery 1988; 23: 733737.

8. Kreth FW, Warnke PC, Ostertag CB. Stereotaktische interstitielle Radiochirurgie und perkutane Radiotherapie in der Behandlung zerebraler Metastasen. Nervenarzt 1993; 64: 108-113.

9. Prados M, Leibel S, Barnett C, Gutin PH. Interstitial brachytherapy for metastatic brain tumors. Cancer 1989; 63: 657-660.

10. Bernstein M, Gutin PH: Interstitial irradiation of brain tumors: a review. Neurosurgery 1981; 9: 741-750.

11. Bernstein M, Laperriere N, Leung P, McKenzie S. Interstitial brachytherapy for malignant brain tumors: preliminary results. Neurosurgery 1990; 26: 371-380.

12. Posner JB, Chernik NL. Intracranial metastases from systemic cancer. Adv Neurol 1978; 19: 579-592.

13. Galicich JH, Sundaresan N, Arbit E, Passe S. Surgical treatment of single brain metastasis: factors associated with survival. Cancer 1980; 45: 381-386.

14. Sundaresan N, Galicich JH, Beattie EJ. Surgical treatment of brain metastases from lung cancer. J Neurosurg 1983; 58: 666-671.

15. White KT, Fleming TR, Laws ER. Single metastasis to the brain: surgical treatment in 122 consecutive patients. Mayo Clin Proc 1981; 56: 424-428.
16. Dosoretz DE, Blitzer PH, Russell AH, Wang CC. Management of solitary metastasis to the brain: the role of elective brain irradiation following complete surgical resection. Int J Rad Onc Biol Phys 1980; 6: 1727-1730.

17. Front D, Even-Sapir E, Iosilevsky G, Israel O, Frenkel A, et al. Monitoring of ${ }^{57} \mathrm{Co}$-bleomycin delivery to brain metastases and their tumors of origin. J Neurosurg 1987; 67: 506-510.

18. Rall DP, Zubrod CG. Mechanisms of drug absorption and excretion: Passage of drugs in and out of the central nervous system. Ann Rev Pharmacol 1962; 2: 109-128.

19. Rosner D, Nemoto T, Lane WW. Chemotherapy induces regression of brain metastases in breast carcinoma. Cancer 1986; 58: 832839.

20. Stewart DJ, Grahovac J, Benoit B, Addison D, Richard MT, et al. Intracarotid chemotherapy with a combination of 1,3-bis(2chloroethyl)-1-nitrosourea (BCNU), cis-diaminedichloroplatinum (cis-platin), and 4'-O-demethyl-1-O-(4,6-O-2-thenylideneB-D-glucopyrano-syl) epipodophyllotoxin (VM-26) in the treatment of primary and metastatic brain tumors. Neurosurgery 1984; 15: 828-833.

21. Cabantog A, Bernstein M. Complications of first craniotomy for intra-axial brain tumour. Can J Neurol Sci 1984; 21: 213-218.

22. Prados MD, Gutin PH, Phillips TL, Wara WM, Sneed PK, et al. Interstitial brachytherapy for newly diagnosed patients with malignant gliomas: The UCSF experience. Int J Radiat Oncol Biol Phys 1992; 24: 593-597.

23. Bernstein M, Laperriere N, Glen J, Leung P, Thomason C, et al. Brachytherapy for recurrent malignant astrocytoma. Int J Rad Onc Biol Phys 1994; 30: 1213-1217.

24. Willis BK, Heilbrun MP, Sapozink MD, McDonald PR. Stereotactic interstitial brachytherapy of malignant astrocytomas with remarks on postimplantation computed tomographic appearance. Neurosurgery 1988; 23: 348-354.

25. Kumar PP, Patil AA, Leibrock LG, Mawk JR, Yonkers AJ, et al. Continuous low dose rate brachytherapy with high activity iodine- 125 seeds in the management of meningiomas. Int $\mathbf{J}$ Rad Onc Biol Phys 1993; 25: 325-328.

26. Gutin PH, Leibel SAR, Hosobuchi Y, Crumley RL, Edwards MSB, et al. Brachytherapy of recurrent tumors of the skull base and spine with iodine-125 sources. Neurosurgery 1987; 20: 938-945. 